\title{
LA RACIALIZACIÓN COMO ESPACIO POLÍTICO: HACIA EL "NEGRO CONSCIENTE” EN EN LA PRISIÓN DE LOS SUEÑOS, DE ELISEO ALTUNAGA
}

\author{
POR \\ Silvia VALERo \\ Universidad de Cartagena
}

La dinámica desarrollada por el movimiento de reivindicación de las negritudes desde los años '80 en América Latina, adquirió características que obligan a sopesar la producción cultural de este período desde categorías diferentes a aquellas vinculadas a la identidad como el sincretismo, la hibridación, la transculturación, el rizoma, etc. Por primera vez la lógica de acción adquirió carácter general: países con diferentes realidades socio-políticas se sumaron al movimiento siguiendo parte del guión transnacional, pero también adoptando singularidades en función de la propia localidad. A medida que el proceso avanzó exitosamente en cuanto a recepción pública y tejido de redes translocales, las voces se multiplicaron, y en algunos casos se diferenciaron en pos de intereses diversos y contrapuestos. ${ }^{1}$

Como detallé en un trabajo dedicado a las literaturas afrolatinoamericanas del siglo XXI ("Literatura"), el campo literario también ha acusado recibo de esta dinámica de manera notable. En la medida en que la literatura es un punto de intersección en el que refractan discursos sociales, los escritores vinculados a una sociedad con una tradición y una presencia cultural de las negritudes con cierto peso son quienes más han tenido para decir en este proceso. El caso de Cuba se constituye paradigmático en razón de que sus condiciones socio-políticas se distancian de las del resto del Caribe, al mismo tiempo que se constituye en el mayor productor histórico de la región de literatura concentrada en "lo negro". 2

1 Para comprender la articulación entre el movimiento de identidades políticas, en este caso en torno a la "etnía" y la "raza", y el espacio discursivo sobre y desde las políticas de identidad afrodescendientes desarrolladas en los últimos años en América Latina, ver Identidades políticas en tiempos de afrodescendencia: Auto-identificación, ancestralidad, visibilidad y derechos. Silvia Valero y Alejandro Campos García, eds.

2 Aunque hablar de "lo negro" puede implicar la generalización de un campo polivalente, lo que quiero significar con el concepto son todas aquellas preocupaciones, tópicos y problemáticas que se mueven a su alrededor: políticas antiracistas, identificaciones, etnicidades, subjetividades, etc., con plena consciencia de que, como dice Stuart Hall, hablar de "lo negro" significa asumir su carácter de constructo político 
El vuelco fundamental que han dado las textualidades discursivas alrededor de este tópico, es que la racialización ya no se erige con una connotación negativa, como denuncia de prácticas discriminatorias desde hegemonías blancas, sino que se asume como identidad, con la preocupación focalizada en hacer de la raza un signo (Segato), esto es, con capacidad de significar positivamente en virtud de una contextualización histórica ligada a un pasado común. Así, en la medida en que el camino de la revisión se instrumentalizó a través de la racialización de prácticas y sujetos, tiene sentido considerar de qué manera la literatura se constituye en torno a la cuestión racial, en tanto esto condiciona el modo de representación.

De allí que este artículo se concentre en la tesis de que la textualización discursiva opera como productora de subjetividades racializadas en pos de una ciudadanía asentada en lo cultural. Es decir que, lejos de ver de qué manera las políticas coloniales, nacionales y postcoloniales dictaminan un cruce relacional basado en parámetros etnorraciales, me interesa explorar cómo se textualiza la negritud desde abajo, esto es, cómo la racialización adquiere tintes políticos desde aquellos mismos sujetos que buscan afirmar una identidad a partir de este proceso de reivindicación.

En este camino, introduzco la novela En la prisión de los sueños (2002) de Eliseo Altunaga (Camagüey, 1941), quien se constituye como el único escritor cubano de este período que ha construido su corpus narrativo -ficcional y ensayístico- alrededor de la negritud, ${ }^{3}$ entendida esta como un terreno en el cual se configuran luchas por los significados, por el dominio de la memoria y de proyectos políticos, culturales y sociales (Laó-Montes 64).

Mi punto de partida es el patrón teórico que hace de virtual trasfondo de la novela y en el que me apoyo para argumentar el posicionamiento deAltunaga. Michelle Wright, en Becoming Black, arguye que lo que une las reflexiones de los intelectuales de la diáspora africana en América, en el siglo XX, no es la búsqueda de una historia y de un tropo cultural comunes sino la metodología teórica que utilizan para sus reflexiones. Según Wright, esta metodología se desplaza entre diferentes formaciones teóricas occidentales, siendo las principales las dialécticas hegeliana y marxista y el dialogismo bajtiniano. Es en esta línea que Altunaga reconceptualiza la identidad negra cubana alrededor de

y cultural y, por lo tanto, la imposibilidad de pensarlo como una categoría unificadora ("¿Qué es 'lo negro'?". Para ampliación del tema ver Silvia Valero, "Figuraciones de 'lo afro’ y 'lo negro' en la cultura cubana".

3 En otro trabajo integré en este concepto también a la escritora cubana Marta Rojas. Sin embargo, marcaba que, entre ambos escritores, se produce un juego de visualizaciones diferentes en la medida en que sus lugares de enunciación son opuestos: mientras Rojas se ubica dentro de la idea oficial de la unidad en torno a la redefinición de la identidad nacional que opera a partir de los '90, Altunaga se instala en el debate actual por el lugar del negro en la sociedad cubana (Mirar atrás). 
la lucha interna del propio personaje negro que, desdoblado en un alter ego, oscila entre ambas dialécticas, y puede leerse como un apunte autobiográfico del mismo autor.

Este proceso de racialización en su narrativa, que se articula con otro de "autodeterminación"(Valero, "Mapeando"y Mirar atras), se convierte en fundacional de la narrativización si consideramos el cambio de perspectiva con que Altunaga representa prácticas y sujetos a través de un doble mecanismo: la subversión de paradigmas literarios e históricos establecidos y el relato de acontecimientos históricos a los que se instituye como fundacionales.

\section{RACIALIZACIÓN Y CRUCE DIALÉCTICO}

Eliseo Altunaga, guionista de cine y profesor de Guión en la Escuela Internacional de Cine de San Antonio de Los Baños, publicó el libro de cuentos Todo mezclado en 1984. Cuatro años más tarde, presentaría su primera novela, Canto de gemido, donde el macroespacio del Caribe durante el siglo XVII actúa como referente témporo-espacial. Ambos textos acentúan lo que será luego la obsesión de Altunaga: constatar, a través de personajes ficticios e históricos, la acción conjunta de esclavos y esclavizadores en la construcción de la historia política, económica y cultural del Caribe. Estos serán los intentos iniciales por ubicar al negro como referente ineludible de la identidad caribeña, oponiéndose, así, al habitual concepto de "aporte" a una cubanidad ya conformada unilateralmente por la presencia europea.

Entrados los años '90, Altunaga ingresa en lo que considero la etapa cubana de su obra en tanto concentra sus tramas en momentos fundantes de la historia de la isla. Si en la novela $A$ medianoche llegan los muertos (1998) el núcleo se situaba en la avanzada del General Antonio Maceo hacia el occidente de Cuba durante la guerra de independencia, con En la prisión de los sueños ${ }^{4}$ abre el espectro histórico para reflexionar sobre otros episodios menos invocados por la literatura, como la Guerrita del ' $12^{5} \mathrm{o}$ la Revolución y el posterior Período Especial. En cuanto a estos dos últimos, lo que quiero significar es que, con la narrativa de Altunaga, por primera vez en la literatura

\footnotetext{
4 En adelante, En la prisión.

5 En 1908 se forma en Cuba el Partido Independiente de Color (PIC) declarado ilegal en 1910 por una enmienda a la Constitución creada por el senador mulato Morúa Delgado, que respondía a su ideal integracionista: "Creo perfectamente inconstitucional la agrupación política, la organización de cualquier partido, su existencia en nuestra República, siempre que ese partido tienda a agrupar a los individuos por motivos de raza, o de clase, siempre que esa raza no contenga en sí los elementos étnicos todos de que se compone la sociedad cubana" (Morúa Delgado 241). Ésta fue la causa que llevó a miles de negros a un levantamiento en las montañas de Santiago de Cuba, a la que le siguió una represión por parte del Ejército republicano. Un acercamiento al primer documental sobre el tema, "1912. Voces para un silencio", de Gloria Rolando, se puede ver en "Afroepistemología ..." (Valero).
} 
se pone en cuestionamiento el lugar del negro en la sociedad cubana de los últimos 50 años. ${ }^{6}$ Esto no puede pensarse sin tener en cuenta, por un lado, las condiciones históricas que favorecieron a Altunaga - y a otros escritores- en cuanto a la apertura de la agenda cubana en lo que se refiere a los discursos de la identidad, y por otro, el movimiento reivindicatorio a nivel continental -y global- al que hacía referencia el inicio de este artículo. En este punto, entonces, me parece necesario leer la manera en que Altunaga da cauce a la lucha, ya no solo social sino también intelectual y subjetiva, del personaje negro cubano.

La estructura de En la prisión consta de diferentes niveles narrativos interconectados, aunque el eje dramático se desarrolle a través de los relatos que el Profesor, un negro militante de la vanguardia política revolucionaria cubana, sueña que, a su vez, sueña que narra a un grupo de negros durante un agobiante verano habanero de los años ' 90 . Todo sucede dentro de una prisión y los personajes de los relatos son los mismos con quienes, en sueños, comparte ese espacio. En sus momentos de vigilia, el Profesor es un hombre que deambula por las calles de Centro Habana, siendo testigo y parte de la terrible situación socio-económica en que se vio sumida la Isla durante el Período Especial. Este punto de apoyo espacio-temporal le permite al autor hacer una apelación más directa para entrar en la discusión actual y desde allí establecer el diálogo con el pasado. Esto significa que, aunque los hilos que estructuran ideoestéticamente a En la prisión renuevan los de A medianoche llegan los muertos -la realidad construida a partir de imágenes, la distancia entre el relato histórico y el hecho, el lenguaje como obstáculo, la convicción de sobrevivencia del negro en una nación blanqueada ideológicamente, la presencia viva de la religiosidad afrocubana-, Altunaga integra esta novela en el debate por el lugar del negro en el sistema socialista cubano, tras la imagen revolucionaria del uno indivisible. Pero lo interesantes es que, si bien los mecanismos de significación que pone en juego en sus obras, esto es, coordenadas socio-históricas re-elaboradas, memorias y tradiciones re-inventadas, escenarios estéticos, elección de lenguajes y materialidad textual, disponen un régimen de representación dirigido a desmenuzar la columna interior que sostiene el régimen de verdad del poder, todo ello está puesto en función de un objetivo mayor que es el de introducirse en las posibles subjetividades negras para, desde allí, abrir el juego.

En este sentido, así como en A medianoche llegan los muertos el autor se preocupó por descomponer los a priori históricos racializados ocultos tras los argumentos que sostienen que en la Guerra de Independencia se fraguó la fraternidad racial cubana, ${ }^{7}$

6 Quizás una excepción la constituya Manuel Granados con su novela Adire y el tiempo roto (1967).

7 Para un análisis de $A$ medianoche llegan los muertos ver Silvia Valero, "De 'negros' y 'mulatos' en la literatura cubana contemporánea: Eliseo Altunaga, Marta Rojas y la re-escritura de la historia" y Mirar atrás. La importancia del pasado en los relatos de nación y negritud en la literatura afrocubana de entre siglos. 
el mecanismo representacional de En la prisión desmontará la dialéctica del amo y el esclavo como régimen de verdad para, finalmente, por oposición, proponer como síntesis al "sujeto negro consciente", en el sentido fanoniano del concepto.

Utilizando libremente como trasfondo metodológico-teórico las dialécticas hegeliana y marxista, el autor crea un contrapunto ideológico del Profesor al que éste, en la inconsciencia del sueño, le da voz para que lo interpele en el núcleo mismo de su conflictividad, es decir, en su "conciencia racial", a partir del espacio ocupado dentro del orden que acató. Este personaje, a quien Altunaga denomina irónicamente Chucho Hegel, debate con el Profesor acerca de la interpretación de la historia cubana y la presencia del negro en ella, pero sobre todo, confronta con la actitud y el discurso del Profesor, a los que lee como resultado de las políticas revolucionarias a nivel de la subjetividad.

Las discusiones entre el Profesor y Chucho Hegel, quien no es otro que el alter ego del primero, se intercalan entre los cuentos fragmentados del Profesor a los otros presos, formando una suerte de cajas chinas, sólo aparentemente independientes de la totalidad de la obra. En realidad, la función de estos relatos es, por un lado, complementar la idea de Altunaga de que la historia del negro es una sola, recurrente a lo largo del tiempo $\mathrm{y}$, por otro, ir prefigurando la puesta en juego de las dialécticas alrededor de los dos personajes principales, el Profesor y Chucho Hegel.

De aquellos relatos, es necesario rescatar los titulados "Negro" y "Niña". Lo que podría sospecharse como una historia más de esclavos y cimarrones ambientada en una hacienda azucarera, adquiere, sin embargo, otras connotaciones cuando Altunaga invierte sus términos: Niña, entregada a actividades orgiásticas con su esclavo Negro y Francés, el médico, descripta con rasgos sensuales, ardientes, a la inversa de la figura angelical de la mujer blanca con que alimentó el imaginario la literatura anti-esclavista, suma a su caracterización la paradoja de ser activa participante de los ritos religiosos de sus esclavos, aun cuando se ha formado intelectualmente en Francia.

Negro, por su parte, es el esclavo doméstico al que Niña seduce y luego incita a huir para evitar su sacrificio, en oposición a las imágenes del acosador y violador de mujeres blancas que se instala, sobre todo a partir de la República, cuando intenta reflotarse el "miedo al negro" frente a la formación del Partido Independiente de Color. Este desvío que realiza Altunaga de dos presupuestos básicos como son el esquema clásico de la mujer blanca deseada por el negro lascivo y salvaje, y el de la joven hacendada formada en Europa -aunque, en este caso, trascienda esos saberes-, parece perder su naturaleza cuando Negro, quien ha huido a instancias de Niña, es finalmente atrapado, torturado y sacrificado, con lo cual la tradición literaria parecería quedar intacta. La pregunta que surge, entonces, es ¿qué sentido se infiere de la tortura y muerte del esclavo Negro, si, como argumenté más arriba, en las obras de Altunaga se instalan el cimarronaje y la resistencia, entre otros cronotopos históricos, como núcleos fundacionales de la acción 
política del negro? Por otro lado, también podríamos preguntarnos si la transculturación de Niña opera sólo como representación de la construcción de la cubanidad, tal como entiende Altunaga a esta última. ${ }^{8}$

Responder a estas preguntas implica, necesariamente, encontrar su punto de articulación con las historias personales del Profesor y Chucho Hegel. Algo similar a lo que ocurre con otra serie de relatos en la que Altunaga introduce episodios referidos a la Guerrita del '12, como evento que refuerza la condición de víctima del negro y con lo cual busca modificar el imaginario social con respecto a su percepción. De allí que ponga en cuestionamiento la transmisión de la memoria a través de la imagen, ${ }^{9}$ televisiva en este caso, de una versión de la historia que no se corresponde con la que sostiene la novela pero que es tan poderosa como para crear una "garantía de verdad" (Hall, "Subjects" 290): ${ }^{10}$

Pensé en usted y lo que me decía de su abuela y esa guerrita que nadie conoce, cuando dijeron la fecha en la novela, pero lo de la televisión lo deja clarito: no mataron a los negros, sino a los emigrantes españoles que querían hacer sindicatos. No me va a decir que usted sabe más que la televisión. (En la prisión 67)

La racialización que producen los textos como los de Altunaga es concebida en el contexto de la historia de los pueblos africanos esclavizados y sus descendientes sojuzgados en América, en razón de lo cual, lo más significativo del diálogo entre el Profesor y el emisor del párrafo anterior, un joven barrendero con quien el Profesor sostiene un diálogo ocasional, es que, al mismo tiempo que aquel descree de la matanza, actualiza antiguos estereotipos reforzados por imágenes que construyen el imaginario social. ¿Qué otra cosa hace Altunaga, sino problematizar la axiología revolucionaria del fin del racismo cuando pone en boca del barrendero el siguiente párrafo?:

Hace poco me llevé unos periódicos extranjeros y uno decía que los negros tienen el cerebro más chiquito que los blancos y que por eso eran tan brutos [...].

A mí me parece que deben tener el cerebro más grande o más chiquito, porque miro la televisión y veo a unos negros matando a otros negros, y miro y veo en California a unos blancos matando a palos a un negro. Y nunca he visto por la televisión a un negro matar a palos a un blanco. Algo distinto tienen que tener porque todos mis puercos me engordan igual cuando les doy buena comida. (88)

8 Altunaga sostiene que la identidad cubana fue haciéndose con el intercambio equilibrado de factores culturales europeos y africanos y que, entre ambos, construyeron la cubanidad. De allí que se niegue a hablar de "afrocubanidad" (ver Valero, "Figuraciones").

9 Altunaga desarrolla este pensamiento en su artículo "La imagen que se evade".

${ }^{10}$ Stuart Hall habla de la "lógica discursiva" como "[...] a logic in which, of course, the biological trace still functions even when it's silent, bur now not as the truth, but as the guarantor of the truth. That is a question of discursive power" (290).

$111 \frac{\text { Revista Iberoamericana, Vol. LXXXII, Núms. 255-256, Abril-Septiembre 2016, } 573-586}{\text { ISSN 2154-4794 (Electrónico) }}$ 
Episodios como este son los que funcionan como disparadores de la crisis del Profesor, la cual, azuzada por la voz de Chucho Hegel, le sirve a Altunaga para asumir una posición crítica contra aquellos negros quienes, décadas antes, acataron una política revolucionaria que los privó de su diferencia cultural. En otras palabras, la novela construye al Profesor como uno de aquellos que, desde la perspectiva actual de algunos intelectuales negros cubanos, se han asumido como un Uno sin caer en la cuenta de que eran un Uno parcial, es decir, un "casi lo mismo" pero no igual.

Es aquí donde se logra la articulación con las historias de Negro y Niña que confluyen para convertir en signo semiótico el final trágico de Negro y el proceso de transculturación de Niña. Esta no solo se compenetra con el mundo de los negros sino que comienza a abandonar las lenguas de las metrópolis para hablar las africanas. El compromiso del personaje con el mundo negro-esclavo, sin embargo, tiene su límite: cuando Niña observa a su esclava Negrona, ${ }^{11}$ quien se acuesta todas las noches con Amo, el Profesor- narrador nos dice que la esclava

[...] tal vez sintió su presencia y giró la cabeza, se turbó un instante y sonrió con sus labios gruesos y sus dientes parejos blancos como las sábanas. Tenía el cuello largo y las nalgas altas, "es hermosa como una yegua hermosa", pensó Niña, "pero es esclava". Y Niña, aunque supiera de Derecho Romano no podía tener celos de una esclava lavandera de su propia dotación. (11, el destacado es mío)

Con esta afirmación comienza a tomar forma la dialéctica hegeliana: en una nueva alocución propia del Iluminismo, Niña puede ser elocuente en la retórica reformista -"delante de los sirvientes hablaba [...] de la libertad de los hombres para vender su trabajo" (140)-, pero esto no implica que eleve al esclavo a la categoría de sujeto. En consonancia con ello, Altunaga contraviene la lógica de la resistencia cimarrona cuando hace que Negro, mientras huye a instancias de Niña para evitar su sacrificio, decida regresar a la hacienda porque,

[...] no le gustaba la ciénaga, los jejenes, los mosquitos, [...] Tampoco le gustaban el curujey y los helechos adheridos a los árboles. Ni los mangles con sus raíces tejidas dentro del agua oscura [...] Su vida había terminado para comenzar otra que no había escogido y que no quería mantener. No le gustaba andar embadurnado, quería circular limpio con las pasas sin piojos y la piel olorosa a jabón. [...] Niña necesitaba su fuerza,

\footnotetext{
${ }^{11}$ No es casual que solo tengan nombre propio Chucho Hegel y los amigos del Profesor que no se han perdido en los dogmas del sistema, como sí lo ha hecho el Profesor, así como también Niña, Negrona, Amo, Francés, Esclavo son parte funcional del sistema de plantación. Mientras estos últimos, voluntariamente o no, son funcionales a un orden socio-económico y político, los primeros resisten a la absorción absoluta de sus individualidades.
} 
sus conocimientos, sus sensaciones, toda la fuerza del espíritu. [...] Niña nunca dejaría que le pasara algo malo. Él es su esclavo y ella su ama. Dónde podrá encontrar un esclavo más fiel. (83, el destacado es mío)

Simbólicamente, esta recuperación paródica de la imagen del negro cimarrón valiente de la literatura post-revolucionaria, como Los guerrilleros negros (1979) o Biografía de un cimarrón (1966), anticipa la dialéctica que se verá reproducida en la discusión entre Chucho Hegel y el Profesor. Es aquí, entonces, cuando los relatos se vinculan en el objetivo de proyectar la voluntad de reconocimiento e imitación preanunciados en "Niña" y "Negro", y articulan con la increpación de Chucho Hegel al Profesor: "Sigues siendo el subalterno que se reconoce cuando es de interés para que esencialmente todo siga igual, por eso cuando ese interés desaparece vuelve al inicio" (157). Esto conduce a la interpretación que hace Judith Butler de la dialéctica hegeliana, ${ }^{12}$ según la cual, en el reconocimiento va implícita la autonomía del "esclavo" que al mismo tiempo es un efecto disimulado del poder del "amo" porque éste, desde la perspectiva de Chucho Hegel, ha circunscripto al Profesor-y por proyección, a todos los negros-a una posición alienada en cuanto a su propia identidad cultural y "racial". Lo que no debe perderse de vista es que el Profesor, al desdoblarse a sí mismo en Chucho Hegel y Profesor -las recreaciones oníricas metanarrativas-no hace más que manifestar sus propios demonios interiores, es decir, la tensión vital, ético-cognoscitiva, que lo atormenta.

También el núcleo de la novela anterior de Altunaga, A medianoche llegan los muertos, es la crisis del protagonista, pero, mientras en ese caso el origen era el enfrentamiento de un personaje de la burguesía blanca cubana con un Otro externo, en En la prisión de los sueños el conflicto se produce al enfrentarse el protagonista negro consigo mismo. Esta diferencia no es anecdótica, sino que revela el salto del autor entre una novela y otra: si en la primera sobrevolaba la pregunta retórica "quiénes somos como país", la segunda, más inserta en el marco socio-discursivo de la época, se debate en cuestionamientos acerca de "qué es ser negro" y "qué lugar se ocupa como tal" en la Cuba finisecular.

Esto explica que el autor juegue con la dialéctica hegeliana para ejemplificar el estado de conciencia de los diferentes actores dentro del ensamblaje de poderes en el que, considera, se ha visto históricamente envuelto el negro, sobre todo, a partir de las teorías socialistas del sujeto único. Y por esta misma razón, crea en Chucho Hegel el contrapunto necesario para incorporar en él la dialéctica materialista como oposición y crítica a la "negación de la negación” de la dialéctica idealista, marcando así la diferencia entre una y otra, tal como la explica Michelle Wright: "[...] idealist dialectics simplify

12 "El esclavo trabaja como sustituto, al servicio de la negación; sólo mediante la imitación y el encubrimiento del carácter mimético de su trabajo puede aparecer al mismo tiempo activo y autónomo" (Butler 49). 
the moment of negation by wholly erasing its presence at the moments of synthesis" (16). De este modo, afirma Wright, la síntesis no difiere de la tesis y esto es lo que puede leerse en el concepto de "máscara" que Franz Fanon utiliza para referir al negro con "máscara blanca" que siempre será el Otro, ya que la dialéctica idealista sólo produce subjetividad blanca, por lo cual, cuando Chucho Hegel dice: "Quisieras escribir novelas como Los Miserables, La Comedia Humana o La Guerra y la Paz. Qué gran favor les harías pero no les interesa, Profesor. Eres un subalterno" (127), apunta directamente a una analogía con el error de Negro: creer que es reconocido como un Uno.

Paralelamente, Chucho Hegel increpa al Profesor: "Sin dejar de ser el mismo, te has convertido en el otro como el blanco que se pinta de negro en el teatro bufo" (127). El autor está poniendo en evidencia el mayor de los demonios contra los que lucha el Profesor, un personaje que deja espacio para una lectura autobiográfica que da cuenta de la propia lucha intelectual de Altunaga: su disconformidad, ya no con un sistema, sino consigo mismo. Y en este punto no será Chucho Hegel sino un narrador quien, actuando como la propia segunda voz del personaje, proyecte un pensamiento confesional: "Sales de la funeraria con la amarga sensación que toda tu vida es una mascarada [...] Sientes que creíste con inquebrantable candidez demasiadas cosas" (122).

Altunaga retoma aquí un tópico de la literatura del primer período revolucionario, esto es, el conflicto que produce la contradicción entre la cultura racional, moderna, occidental, y una ideología laica y atea, defendidas por la Revolución y lo que se veía como supersticiones irracionales y primitivas de los negros, constituidas en obstáculos para el avance de aquella. No por azar, aquel estado de desasosiego del Profesor se produce luego de enfrentarse, en un velatorio, a un grupo de negras viejas, cuando su pensamiento reproduce consignas y tonos que se leen en mucha literatura ficcional y ensayística del primer período revolucionario: "Las miras con desdén, con resentimiento, tal vez con odio, porque así pasarán la mayor parte de sus vidas, mirando impotentes a sus muertos, indolentes, invocando espíritus y orishas" (122, el destacado es mío). Baste recordar, a manera de parangón, el prólogo de Pedro Deschamps Chapeaux a la novela de Manuel Cofiño, Cuando la sangre se parece al fuego (1977): el historiador, al señalar como aspectos negativos para ese momento procesal revolucionario a los prejuicios que perduraban desde la colonia y al imperialismo norteamericano, sumaba las religiones - "gentes que se marginan por sí mismas, en suma" (7)-, porque están fuera del contacto con la realidad. Estas reflexiones del historiador cubano, quien afirmaba que "la ideología revolucionaria, siempre en ascenso, vence a las creencias ancestrales" (11), encuentra su eco en el Profesor, cuya formación ideológica entra en conflicto con las religiones afrocubanas, ya que había creído, "con inquebrantable candidez", que "los jóvenes cuadros, educados en Europa, conocedores de la doctrina marxista leninista barrerían de un plumazo ese mundo atávico y dependiente" (111).

Lo que se pone en evidencia en esta instancia es la aparente imposibilidad de que "lo negro" como especificidad haya sido parte de una identidad revolucionaria. Como se

$111 \frac{\text { Revista Iberoamericana, Vol. LXXXII, Núms. 255-256, Abril-Septiembre 2016, } 573-586}{\text { ISSN 0034-9631 (Impreso) }}$ 
señaló al inicio, el momento histórico permite la revisión y crítica de estos paradigmas y En la prisión, como refractaria de ello, opta por difundir una idea de negritud que se acerca a un "deber ser" que se manifiesta en tensión con el anterior "ser revolucionario", cuya etnicidad estaba asentada en el compromiso ideológico y el mérito revolucionario.

Por esta razón, la función de Chucho Hegel, más allá de la condena por el sometimiento mimético, es la de oponer a la figura del Profesor una subjetividad negra, para la cual es necesario asumir "un ser para sí" en cuanto "conciencia racial" que se vería reproducida en la interpretación de la historia y la realidad cubanas, pero, sobre todo, en la conciencia misma del Profesor como sujeto negro. Altunaga vuelve aquí a una de sus obsesiones: la función del lenguaje que nombra al negro. A partir de esta lógica, Chucho Hegel condena el lenguaje del Profesor que, mirado desde su presupuesto racial, no le corresponde: "Eres un mudo o peor, un fenomímico que imagina suyo un discurso ajeno. No tienes lengua propia sino una jerigonza contaminada que te enseñaron [...] Sigues siendo un negro intelectual con la lengua de un blanco" (125-126). ${ }^{13}$ Nuevamente Altunaga se apoya en Fanon, cuya idea del régimen de representación del blanco con respecto al negro va más allá de la idea de posicionarlo como el Otro del discurso dominante. Fanon desmenuza la experiencia colonizadora como el acto de someter a ese Otro a una interiorización de ese "conocimiento" y de esa subjetividad en un proceso que Stuart Hall denominará luego "expropiación interna" ("Subjects" 135). Es por esto que, como contracara del Profesor, Chucho Hegel, quien ha tenido el mismo inicio intelectual del protagonista, ha logrado trascender la falsa dicotomía en la que el negro resulta siempre Otro:

Yo era el negro que creía en la superioridad de la lengua alemana. Pensaba que el pensamiento alemán era lo máximo, Profesor. Era un negro germanista que aprendió alemán para leer a Karl Marx y se enamoró de Hegel y se fue a la República Democrática Alemana a estudiar la teoría del conocimiento y conoció a Feuerbach [....]

Estando en Weimar, un día [...] vi unas camillas montadas en un complejo sistema de cajas de bolas para meter los cadáveres en el crematorio, la más sofisticada tecnología para callar a los que no pensaran como Goethe o como otro, para suprimir las diferencias, para marchar hacia el futuro. (123-25)

Aparentemente, y como ya adelanté, Chucho Hegel se asume como el resultado de la "negación de la negación" pero desde la dialéctica materialista, por lo cual la síntesis lograda es la del negro consciente, un negro con status de sujeto, es decir, una "conciencia para sí'. Leído de este modo, surge del texto una "manera de la negritud" que se acerca al pensamiento de otros intelectuales negros de este nuevo período histórico cubano. Es el caso de, por ejemplo, Elio B. Ruiz quien, en un artículo titulado "La invisibilidad

${ }^{13}$ La preocupación por el lenguaje que nombra al negro es constante en Altunaga y se desarrolla con más profundidad en A medianoche llegan los muertos. 
de Manzano", actualiza el tema del poeta decimonónico y su conciencia como sujeto, en el siguiente tenor:

Incluso hoy no es raro encontrar a intelectuales y escritores negros asalariados que no quieren saber nada de lo negro que ellos mismos son [...]. Dichos escritores afrodescendientes quieren ser aceptados por la cultura institucional y escriben como los blancos para los blancos, con la ilusión de ser aceptados entre los blancos, a pesar de todo. (Ruiz 174) $)^{14}$

En esta línea de pensamiento se coloca la tensión en la que se debate el Profesor, ya que como negro debería, desde esta perspectiva, asumir una visión del mundo determinada por su historia colectiva, con lo cual se establece un falso binarismo entre "auténticos" y "asimilados" que resulta esencialista. Indudablemente, lo que buscan todas estas narrativas - la del Profesor y por extensión la novela en sí misma, y en general las denominadas "de la diáspora"- son regímenes de visibilización legítimos pero que provocan, en algunas instancias, este tipo de bipolaridad en cuanto, al mismo tiempo que producen prácticas y significados, van generando su propia "garantía de verdad" acerca de lo que es ser o no ser negro. Es decir que se conforma un sentido de pertenencia apoyado en la idea de una identidad compartida.

A fin de cuentas, el diálogo del Profesor con Chucho Hegel no es otra cosa que el espacio que Altunaga concede el Profesor para dar cuenta de su propia confusión. Él es uno y el otro, el sujeto fragmentado enfrentado a una realidad que ha perdido el orden anterior. En el último relato de sus sueños, el Profesor, a través de las licencias que le permite el mundo onírico, va sufriendo una transformación que lo metamorfosea en Negro, el personaje de sus relatos:

No te molesta tanto lo perdido, sino lo que has dejado rozando, las cosas sin definir, las ilusiones que desplazaste para acatar las normas. [...] "Vengan todos, te juro por mi madre que estoy solo", dice una voz en el monte. Echas a correr hacia la voz que aparenta el eco de tu grito. Logras dar un salto y asustado corres por las calles. Te acosan los baches y las ratas, los latones de basura desbordados; no escuchas los autos, solo el latir del tambor. Tratas de gritar, de saltar para alejarte, aunque te devore el perro, aunque anillen tus tobillos, aunque te suspendan en una cruz de yaya. (157)

\footnotetext{
${ }^{14}$ Resalto lo negro para remarcar la idea que entiendo surge de aquí: se habla de "lo negro" como de una condición unidimensional y pre-existente, en cuanto se une un color de piel a una obligatoria asunción cultural. En este artículo Ruiz contrapone los escritores negros que condena, al poeta Eloy Machado Pérez, El Ambia, quien, en un juego de negociaciones con "la cultura institucional" inserta en sus trabajos expresiones de la religiosidad afrocubana y la oralidad.
} 
El diálogo con Chucho Hegel le ha devuelto al Profesor una identidad negra que impacta contra los discursos identitarios de la Revolución. En ese tenso descubrimiento de su negritud, el Profesor fue haciendo el camino para dejar graficada la potencialidad de lo irresoluble: el sacrificio de Negro se renueva en él porque, para Altunaga, la historia es una sola. Mientras los negros presos de sus sueños gritan "[...] que abran las galeras para que nos dejen respirar" (158), en clara alusión a los barcos negreros, el Profesor siente que el pecho se le abre como una res: "Te miras el pecho, abierto en dos es sólo un hueco en el piso, en un caldero de hierro, tibio aún, yace tu corazón. [...] La luz inclemente se despedaza sobre la ciudad" (158). Poco antes habíamos leído el final de Negro: "Negro tenía el pecho abierto en dos y le habían sacado el corazón" (147).

\section{CIERRE}

Altunaga, al desarrollar este proceso de racialización y des-racialización en sus personajes, va más allá de la condena al nacionalismo revolucionario. Manteniendo categorías marxistas adaptadas a la identidad racial, se adentra en la conciencia de quienes, aún frente a la visión en perspectiva que da la transformación socio-política del país a partir de los '90, se mantienen en una postura que la novela considera alienada con respecto a su "conciencia racial". Y aquí emerge esta otra categoría problemática que Altunaga no había desarrollado en las obras anteriores con la intensidad que lo hace en esta novela, fruto, seguramente, de un campo discursivo social que se realimenta.

De algún modo, el escritor profundiza la noción de una etnicidad fijada en pautas de comportamiento que deben derivarse de la asunción de una historia en la que se marca una posición al sujeto y se lo integra en la herencia común de una desposesión. La racialidad se propone en términos de opresión y es en este punto donde encontramos que los mismos sujetos racializados invierten la carga negativa con el objetivo de afirmarse en una identidad que los define, con una fuerte impronta en el cuerpo. ${ }^{15}$ Dice Chucho Hegel:

Ese molde está en los huesos, Profesor. Nunca van a aceptar al negro gesticulador y bembón como un modelo de belleza. Por eso los negros son el noventa por ciento de la población penal, le piden el carnet en cada esquina, los detienen a la entrada de un hotel y son escasos en los mejores trabajos. Este país se reconstruye una y otra vez en el espejo de otro porque no le gusta su cara. (Altunaga 126-127)

15 Barot y Bird reconocen la importancia de Franz Fanon en el análisis de la focalización del cuerpo en todas las formas de racialización: "For Fanon, there is a racialization of body and psyche what he sees as the epidermalization of 'race'; this epidermalization is a far more profound and violently harmful process of othering than that involved in discourses of cultural difference" (612-13). 
En otra dramatización de sus contenidos ensayísticos, ${ }^{16}$ Altunaga retoma la idea de que el racismo se regenera en la continua reconstrucción del país con una imagen que no le pertenece. La propuesta del escritor, no solo con En la prisión sino también con el resto de sus trabajos, resulta totalmente innovadora para la literatura cubana. La reflexión en torno a una identidad racializada positivamente se inscribe dentro del cuerpo del discurso social del momento, aportando una mirada crítica hacia el propio negro, no siempre presente en la literatura (afro)latinoamericana de este período. $\mathrm{Su}$ lectura resulta imprescindible para la comprensión de los diferentes estadios por los que atraviesa la denominada "narrativa de la diáspora".

\section{BIBLIOGRAFÌA}

Altunaga, Eliseo. En la prisión de los sueños. La Habana: UNEAC, 2003. A medianoche llegan los muertos. La Habana: Letras cubanas, 1998. "La imagen que se evade". Encuentros de la cultura cubana 12-13 (1999): 51-55. "El otro componente". La gaceta de Cuba 34 (1996): 30-31.

Barot, Rohit y John Bird. "Racialization: the Genealogy and Critique of a Concept." Ethnic and Racial Studies 24/4 (2001): 601-618.

Butler, Judith. "Vínculo obstinado, sometimiento corporal. Relectura de la conciencia desventurada de Hegel". Mecanismos psíquicos del poder. Teorías sobre la sujeción. Valencia: Universitad de Valencia, 2001. 41-73

Deschamps Chapeaux, Pedro. Introducción. Cuando la sangre se parece al fuego. La Habana: Editorial de Arte y Literatura, 1977.

Fanon, Frantz. Piel negra, máscaras blancas. 1954. Buenos Aires: Abraxas, 1973.

Hall, Stuart. "'Subjects in History': Making Diasporic Identities". House that Race Built. William Lubiano, ed. Nueva York: Vintage, 1998. 289-299. “¿Qué es ‘lo negro’ en la cultura popular negra?”. Biblioteca Virtual Universal, 1995. <http://www.biblioteca.org.ar/libros/1899.pdf> 17 julio 2010.

Laó-Montes, Agustín. "Hilos descoloniales. Trans-localizando los espacios de la diáspora africana". Tabula Rasa 7 (2007): 47-79.

Morúa Delgado, Martín. Integración cubana y otros ensayos. La Habana: Comisión Nacional del Centenario de don Martín Morúa Delgado, 1957. Vol. 3.

Ruiz, Elio B. “La invisibilidad de Manzano”. Hispanic Review 28/1 (2009): 167-83.

Segato, Rita. "Raza es signo". Debates sobre ciudadanía y políticas raciales en las Américas Negras. Claudia Mosquera-Lavé;A. Laó Montes y C. Rodríguez Garavito, eds. Cali: Universidad del Valle, 2010. 555-579.

Valero, Silvia. 'Literatura y 'afrodescendencia'. Identidades políticas en la literatura

16 Ver los artículos de Altunaga "La imagen que se evade" y "El otro componente".

$111 \frac{\text { Revista Iberoamericana, Vol. LXXXII, Núms. 255-256, Abril-Septiembre 2016, } 573-586}{\text { ISSNN 2154-4794 (Electrónico) }}$ 
afrolatinoamericana del siglo XX". Revista de Crítica Literaria Latinoamericana 81 (2015): 9-17.

"Afroepistemologíay sensibilización en las narrativas históricas 'afrodescendientes' del siglo XXI". Identidades políticas en tiempos de afrodescendencia: auto identificación, ancestralidad, visibilidad y derechos. Silvia Valero y Alejandro Campos García, eds. Buenos Aires: Corregidor, 2015. 531-578.

Mirar atrás. La importancia del pasado en los relatos de nación y negritud en la narrativa afrocubana de entre siglo. Córdoba: Alción, 2014.

"De 'negros'y 'mulatos' en la literatura cubana contemporánea: Eliseo Altunaga, Marta Rojas y la re-escritura de la historia". Historias enredadas. Representaciones asimétricas con vista al Atlántico. Ineke Phaf-Rheinberger, ed. Berlín: Tranvía, 2011. 117-133.

"Mapeando las narrativas de la diáspora en Cuba: la imaginación de la negritud en la literatura de entre-siglos". Casa de las Américas 264 (2011): 93-105.

"Figuraciones de 'lo afro' y 'lo negro' en la cultura cubana". Orbis Tertius XVI/17 (2011): 41-50. <http://www.orbistertius.unlp.edu.ar/numeros/numero-17/ sumario>. 13 julio 2015.

y Alejandro Campos García, eds. Identidades políticas en tiempos de afrodescendencia: Auto-identificación, ancestralidad, visibilidad y derechos. Buenos Aires: Corregidor, 2015.

Wright, Michelle. Becoming Black. Creating Identity in the African Diaspora. Durham y London: Duke UP, 2004. 